\title{
"It's a way of life": Results from the Perceptions of Pain in Haemophilia study
}

Kate Khair, Jarek Kriukow, Mike Holland

Introduction: Pain is recognised as a subjective phenomenon, often defined as 'whatever the experiencing person says it is, existing whenever the experiencing person says it does'. Pain is a critical aspect of life for many people with haemophilia (PWH) but is under-recognised and inconsistently managed by clinicians. As haemophilia management moves towards non-factor-based treatments which may normalise life experience, it is unclear how this will impact on the experience and management of pain. Aims: The Perceptions of Pain in Haemophilia study aimed to identify the impact of pain on men with haemophilia in the UK. Methods: The study used mixed qualitative research methods (paper-based questionnaires and focus group interviews). Eligible $\mathrm{PWH}$ aged $>18$ years were invited to participate in a focus group to discuss pain, assessment and management. Each focus group discussion was recorded, transcribed and analysed thematically. Results: Eighteen participants (13 haemophilia A (12 severe) and 5 severe haemophilia $B)$ age range $18-58$ years (median 32.5 years) joined

KATE KHAIR

Haemnet, London, UK. Email: kate@haemnet.com

JAREK KRIUKOW

Qualitative Researcher Dr Kriukow, Edinburgh, UK

MIKE HOLLAND

Haemnet, London, UK

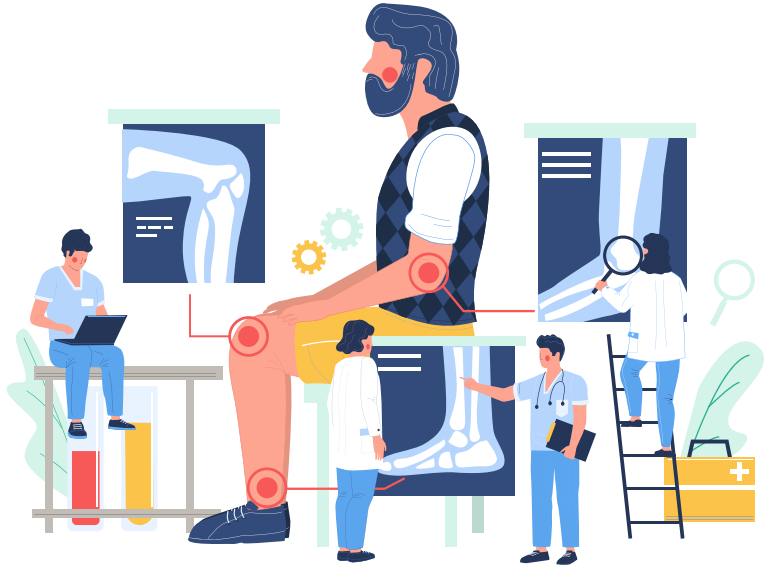

With chronic pain being accepted by many people with haemophilia as part of everyday life, there is a need to better address its social and psychological impacts and to improve awareness of treatments beyond analgesia. As new therapies for haemophilia continue to improve, we must also be cognisant that new therapies will not resolve old pain.

focus groups conducted using an online video platform. The majority (95\%) were treated with prophylaxis and reported few recent bleeds. Three main themes emerged: the impact of pain, managing pain, and factors influencing the experience of pain. Participants connected their earliest experiences of pain with childhood; it impacted their mental health and wellbeing, daily habits, routines, sports, hobbies, social life, work and education. Participants recognised the difference between the pain of acute bleeds and arthritic pain. Many did not like taking strong analgesics

This is an Open Access article distributed under the terms of the Creative Commons Attribution-NonCommercial-NoDerivs License (https://creativecommons.org/licenses/by-nc-nd/3.0/) which permits use and distribution in any medium, provided the original work is properly cited, the use is non-commercial, and no modifications or adaptations are made. Copyright is retained by the authors. 
due to side-effects and concerns around addiction. Participants doubted the value of pain scales and noted a lack of empathy and understanding among health care professionals (HCPs), but valued physiotherapists. Participants recognised the value of talking about the negative impact of their pain experiences; however, they reported that family members, who often provided the most support, could not always truly understand their pain. Conclusion: Pain is 'normal' for PWH, who adopt it into part of their everyday life experience. HCPs are ideally placed to impact this experience but seem to lack insight as to the extent of pain and how to manage it beyond prescribing stronger analgesia. The social and psychological implications of chronic pain should be better addressed by HCPs. This includes being cognisant that new therapeutic options will not resolve old pain.

Keywords: pain, chronic pain, analgesia, haemophilia, patients' views,

ain is recognised as a subjective phenomenon, often defined as 'whatever the experiencing person says it is, existing whenever the experiencing person says it does' ${ }^{[1]}$.

The International Association for the Study of Pain recently redefined pain as 'an unpleasant sensory and emotional experience associated with, or resembling that associated with, actual or potential tissue damage' [2]. They go on to state that 'pain is always a personal experience that is influenced to varying degrees by biological, psychological, and social factors' which are 'affected by life experiences' and 'may have an adverse effect on social and psychological well-being'. So, pain is what the patient says it is - yet people with haemophilia $(\mathrm{PWH})$ do not discuss their pain, and neither do health care professionals (HCPs) ask about it ${ }^{[3]}$. While Tagliaferi et al. ${ }^{[4]}$ report pain as under-recognised and inconsistently managed by clinicians, pain is a critical aspect of life for many PWH. Acute pain serves as a warning sign for bleeding, but after multiple bleeding episodes may become chronic, distracting, and debilitating ${ }^{[5]}$. Chronic pain is complex and is associated with neurobiological, psychological, and social changes. In haemophilia, it has been defined by a consensus of medical experts as 'continuous and/or intermittent pain, related to the pathophysiology of haemophilia, requiring intervention (pharmacological or nonpharmacological pain treatment), in which the cause of pain cannot be readily removed' [6].
Estimates of the prevalence of chronic pain in haemophilia vary depending on the definitions used, the population studied and the methodology employed. Overall, some $32-50 \%$ patients report living with chronic pain ${ }^{[7,8,9]}$. Although $\mathrm{PWH}$ are frequently taught that pain is an early warning sign of active bleeding, which requires prompt treatment, pain may also arise due to damage to the musculoskeletal system and development of haemophilic arthropathy caused by recurrent bleeds.

The haemophilia population comprises multiple cohorts varying by age, treatment type and duration, joint health, inhibitor development and transfusionrelated infection, each of which may affect the level of pain. It is frequently assumed that pain in haemophilia is generally a concern for older patients with joint problems. However, young, well-treated individuals with severe haemophilia may experience more pain than is commonly assumed ${ }^{[10]}$. In the SO-FIT study, well-treated boys with severe haemophilia in the UK reported good quality of life and physical function ${ }^{[11,12]}$. Nevertheless, pain-related questions in three different assessments showed statistically significant deficits that impacted on overall quality of life scores.

Haemophilia management is moving towards non-factor-based treatments such as non-factor replacement therapies and gene therapy, which may normalise life experience and improve activity. It is unclear how this will impact on the experience and management of pain: older PWH will still have preexisting haemophilic arthropathy, 'micro-bleeds' may still occur, and activity levels may increase due to confidence in treatment with a resulting increase in injury related bleeding. In addition to these 'unknowns', non-factor-based treatments may also change approaches to how pain is managed, for example prompting a more liberal use of analgesia currently contra-indicated due to bleeding side-effects. The impact of pain on $\mathrm{PWH}$ requires quantification; the purpose of this study (Perceptions of Pain in Haemophilia) was to identify the impact of pain on $\mathrm{PWH}$ in the UK and to describe PWH's perceptions of current pain management by haemophilia health care providers.

\section{METHODS}

Perceptions of Pain in Haemophilia is a crosssectional, non-interventional study using mixed qualitative research methods (an anonymous paperbased questionnaire and focus group interviews) to explore pain in males with haemophilia in the UK. The 
questionnaire, designed to address the prevalence and perceptions of pain, was developed by a panel of experts and distributed by post to 2,433 men with haemophilia, regardless of severity, age or treatment, by 11 participating haemophilia centres. A total of 599 (24.6\%) responses were received; this data will be presented elsewhere.

At the end of the questionnaire, participants were asked to provide their name and email address if they wanted to be contacted by the research team to participate in an online focus group. Using this contact list and through advertisements on UK social media sites, UK males with haemophilia aged $>18$ years were invited to participate in a focus group. We were pragmatic about recruiting participants but aimed to ensure, as far as possible, that a diverse range of experience was presented. Each focus group included participants across age ranges, with haemophilia $A$ or $B$ and a variety of current treatments. The discussion was moderated by a researcher with experience in clinical haemophilia care and structured using an interview guide (see Appendix) to elicit the nature of acute and chronic pain and to discuss the currently used pain assessment tools for acceptability (length, questions asked) and validity (asking the right questions, whether or not they adequately reflect day-to-day pain experiences).

Each focus group discussion was digitally recorded and transcribed verbatim (with participants anonymised to a study number) and manually coded after each focus group took place. The themes identified were then raised in subsequent focus groups (e.g. by saying "Others have said ... do you agree with this?"). Finally, all transcripts were re-analysed using NVivo 12 by a second member of the study team. After the initial coding of each transcript, all codes were refined and organised into a common thematic framework which was agreed with all researchers. The data from the focus groups are presented in this paper.

Ethical approval was granted for the questionnaire via the HRA, study number 19/NW/0608. The focus groups were deemed to not need full ethical approval using the MRC research tool (http://WwW. hra-decisiontools.org.uk/research// as there was no randomisation or change to treatment and findings would not be generalisable. Consent was assumed for those completing the questionnaire and taken verbally before recording the interviews.

\section{RESULTS}

Thirty-two PWH expressed an interest in participating in the focus groups; five were ineligible (non-UK $n=3$, not
Table 1. Participant demographics

\begin{tabular}{|c|c|c|c|}
\hline $\begin{array}{l}\text { PARTICIPANT } \\
\text { NUMBER }\end{array}$ & $\begin{array}{l}\text { HAEMOPHILIA } \\
\text { DIAGNOSIS* }\end{array}$ & AGE & $\begin{array}{l}\text { CURRENT } \\
\text { TREATMENT }^{+}\end{array}$ \\
\hline 01 & A & 18 & $\mathrm{EHL}$ \\
\hline 02 & B & 22 & $\mathrm{EHL}$ \\
\hline 03 & A & 39 & SHL \\
\hline 04 & A & 33 & SHL \\
\hline 05 & B & 27 & $\mathrm{EHL}$ \\
\hline 06 & B & 21 & $\mathrm{EHL}$ \\
\hline 07 & A & 42 & $\begin{array}{l}\text { Bi-specific } \\
\text { antibody }\end{array}$ \\
\hline 08 & A & 57 & $\begin{array}{l}\text { Bi-specific } \\
\text { antibody }\end{array}$ \\
\hline 09 & B & 37 & $\mathrm{EHL}$ \\
\hline 10 & A & 40 & $\mathrm{EHL}$ \\
\hline 11 & A & 25 & $\begin{array}{l}\text { Bi-specific } \\
\text { antibody }\end{array}$ \\
\hline 12 & A & 58 & $\mathrm{EHL}$ \\
\hline 13 & B & 32 & $\mathrm{EHL}$ \\
\hline 14 & A & 40 & SHL \\
\hline 15 & A & 22 & $\begin{array}{l}\text { SHL (on } \\
\text { demand) }\end{array}$ \\
\hline 16 & A (moderate) & 18 & SHL \\
\hline 17 & A & 57 & $\begin{array}{l}\text { Bi-specific } \\
\text { antibody }\end{array}$ \\
\hline 18 & A & 32 & $\begin{array}{l}\text { Bi-specific } \\
\text { antibody }\end{array}$ \\
\hline
\end{tabular}

* All severe unless noted otherwise

${ }^{\dagger}$ All prophylaxis unless noted otherwise

EHL: extended half-life factor; SHL: standard half-life factor

male $n=1$, not haemophilia $n=1$ ). Eighteen participants, age range $18-58$ years (median 32.5 years) joined one of three focus groups lasting an average of 65 minutes (range 58-76 minutes), with five to seven participants per group. Nine who had expressed interest declined focus group invitations.

Thirteen focus group participants had haemophilia $A$ (12 severe, 1 moderate), five had severe haemophilia $B$. There were no participants with inhibitors. The majority (95\%) were currently treated with prophylaxis (only two participants had received primary prophylaxis) and reported few recent bleeding episodes. Further participant demographics are presented in Table 1.

Three main themes emerged: factors influencing the experience of pain (including 13 sub-themes mentioned 108 times), ways to manage pain (including eight subthemes mentioned 86 times), and the impact of pain (including six sub-themes mentioned 32 times). These are reported in more detail below with direct quotes 


\begin{tabular}{|c|c|c|}
\hline THEME / SUB-THEME & $\begin{array}{l}\text { HOW MANY FOCUS } \\
\text { GROUPS DISCUSSED IT } \\
(\mathrm{N}=3)\end{array}$ & $\begin{array}{l}\text { TOTAL NUMBER OF } \\
\text { TIMES DISCUSSED }\end{array}$ \\
\hline Factors influencing the experience of pain & 3 & 108 \\
\hline Quality of support and treatment from HCPs & 3 & 51 \\
\hline - Over-reliance on painkillers & 3 & 11 \\
\hline - Confusing and invalid scales for assessing pain & 3 & 9 \\
\hline - Lack of empathy and understanding & 3 & 9 \\
\hline - Support from physiotherapists and haemophilia centres & 3 & 7 \\
\hline - Irrelevant treatment and lack of knowledge about the condition & 2 & 13 \\
\hline - Changes of specialists & 1 & 2 \\
\hline Being able to talk to someone about the pain & 3 & 16 \\
\hline Current state of knowledge & 3 & 12 \\
\hline People's lack of awareness of haemophilia & 3 & 10 \\
\hline Ageing & 3 & 8 \\
\hline Understanding own pain and reacting to it & 2 & 7 \\
\hline Masking pain & 2 & 4 \\
\hline Ways to manage pain & 3 & 86 \\
\hline Accepting and getting used to pain & 3 & 26 \\
\hline Physical activity and managing through the pain & 3 & 15 \\
\hline Taking medication & 3 & 13 \\
\hline Maintaining a positive mindset & 3 & 9 \\
\hline Adjusting movement/position & 3 & 7 \\
\hline Using ice & 2 & 7 \\
\hline Using crutches & 1 & 2 \\
\hline Other (yoga, hot baths, other focus) & 2 & 7 \\
\hline The impact of pain & 3 & 32 \\
\hline Mental health & 3 & 11 \\
\hline Daily habits/routine & 3 & 8 \\
\hline Sport and hobbies & 3 & 7 \\
\hline Work & 2 & 3 \\
\hline School and education & 1 & 2 \\
\hline Social life & 1 & 1 \\
\hline
\end{tabular}

attributed to participants by study number (P1-P18) and reflect the views expressed by the participants. Table 2 summarises the themes and sub-themes discussed.

\section{Factors influencing the experience of pain}

The most discussed factor related to participants' experiences of pain was the quality of support and treatment from HCPs. Over-reliance on analgesia prescription was noted as an issue, with one participant reporting haemophilia HCPs being quick to prescribe "some codeine and, if you're lucky, morphine or something of the sort, and then you have to leave" (P3). Another commented he found it "scary" that his doctor "didn't bat an eyelid when I was taking 10 or
12 tramadol a day" (P17) and was only concerned with whether the pain went away.

Likewise, participants felt that general practitioners freely prescribed analgesia:

"I probably could walk into a GP and say, "I have 'haemophilia', and they'd just throw pain medication at me to get me away." (P18)

"You can walk in and say, 'I've got pain, I'm a haemophiliac, I want some really strong drugs. Can you give them to me?' and they can't scribble it out fast enough. It's like, 'Yes, yes, yes, fine. Go on, get out.'" (P17) 
A lack of empathy and understanding from medical staff was reported. Participants felt that doctors would rather prescribe medication and have them leave than empathise with them and care about how they felt. They also raised concerns that HCPs fail to ask questions which show concern about their health:

"No one said, 'What did you do about it? How did you treat it?' It's almost like, 'You got a bleed, you treated it, you're fine now, move on."' (P17)

"One of the challenges is if you do admit you have pain, it's what happens with that information if you give it to your haemophilia team. And if nothing happens with it, then it kind of reinforces 'Well, they're not interested.' There is a sense sometimes that the haemophilia team are interested in bleeding, like, 'Are you actively bleeding? If you're not, why are you here, why are you bothering us with this?"' (P18)

One participant reported no longer seeking help from HCPs "because I've done that so many times and they just advise the same thing which doesn't help me" (P1). Several participants described never being asked about their wellbeing unless via quality of life (QoL) assessment tools or pain scales which they found unhelpful:

"I feel like it's one way of trying to generalise the pain, but it doesn't really... it doesn't really tell you what it really means. [...] It's like saying 'How happy are you on a scale of 1 to 10 right now?' Happy is a variety of emotions and you can feel it in a lot of different ways, and it's similar with pain." (P15)

"My ten could be someone else's four [...] I don't think it's something that you could take all of us together and look at our pain scales and get an average, because we don't know each other's pain." (P4)

In addition to the reliability of these scales, participants questioned their validity, particularly the use of 'face' scales to rank pain:

"For a long time it wasn't a 1 to 10; basically they had faces. So, there was a very unhappy face, a slightly less unhappy one, up to the neutral one to the super-happy one. I don't know why you'd pick super-happy if you were in pain, but anyway...." (P11)

Not all comments about HCPs were negative. Several participants mentioned good support from physiotherapists and the staff at their haemophilia centres. They described these HCPs as being conscientious and thorough, and indicated that they seem to understand the patient's point of view and allow them flexibility in their approach to handling pain:

\begin{abstract}
"He's there when I go for consultations and he just does a joint score and just says, 'How are things?' And he just says, 'If you're comfortable just doing what you're doing, then carry on with what you're doing.' There's no pressure for me to do anything more than that, the physio just says, 'Look, if you're happy just doing that, then just do whatever you're happy with and don't push yourself too much.'" (P17)
\end{abstract}

In all focus groups, participants discussed being able to talk about their pain to someone who understood and who had similar experiences.

"It's really useful [...] having someone that implicitly understands it and you don't have to find that vocabulary." (P18)

This included other affected family members:

$$
\begin{aligned}
& \text { "My brother [...] he's in the same boat - both } \\
& \text { severe and we'll quite often talk or message." } \\
& \text { (P9) }
\end{aligned}
$$

Support and understanding from wives and mothers were also reported as being important. However, many felt that there were few people, including their families and those closest to them, who could truly understand their experience of pain:

"I tried telling people that my ankle hurts, but they don't understand. Like my mum and that, I'll tell them how much it hurts, but you don't understand the extent that it hurts." (P1)

"There's not many people I talk to about pain, because my mum, dad, brother, no one understands how it feels and what it's like." (P16) 
Deliberately not sharing how they felt was one of the factors that negatively influenced participants' experience of pain. One older participant reported doing this throughout his life, and during the discussion advised "the young lads here to open up about it" (P17). Participants' experience with regard to haemophilia treatment was also an influential factor. Several older participants noted that, having been treated on demand as young children, they experienced arthritic pain despite now being on prophylaxis due to earlier joint damage:

"By the time I got onto prophylaxis I think it was way too late, the damage had been done [...] my pain is not necessarily haemophilia related; it's arthritic pain." (P14)

\section{Ways to manage pain}

The participants had developed ways to manage pain; however, many reported this was simply a case of 'accepting and getting used to it':

\section{"You just become used to this kind of pain, it's just part of having the condition" (P17)}

Members of all three focus groups stated that they had developed a "high pain threshold" and accepted living with their pain as "a way of life" (P7). One 23-year-old with severe haemophilia B described having to accept pain in order to live a good QoL:

\section{"If you want to wrap them [haemophiliacs] up in cotton wool, then they might not experience pain, but none of us will ever want to do that. [...] I might be in pain, and that's just an acceptance [...] but then that's also quality of life. I'd rather... Sometimes the quality of life has to be accepted with pain, unfortunately, and that's just the kind of situation of being a haemophiliac." (P2)}

When discussing the practice of 'accepting the pain' and 'getting used to it', all three focus groups discussed using physical activity to manage pain:

\footnotetext{
"My ankle might be stiff, but one of the things I find is just going out for a walk, even just 10-15 minutes, just to move and actually move the joint [...] just getting up and moving more - it actually helps with the pain, reduces the pain." (P10)
}

Participants were able to explain the difference between arthritic pain and bleed pain and knew which and how much exercise could minimise it. One described taking "the path of least pain and training yourself to walk a certain way so that the pain kind of reduces" (P7), while another said, "I completely restructured how I threw a ball" (P2).

Participants reported 'hating' taking painkillers, for two main reasons: the side effects caused and perceived issues of addiction:

"I am on painkillers. I hate taking the likes of
codeine and other stuff because it does upset
your stomach and whatnot and make you
drowsy." (P9)

"I find the side-effects of tramadol far too strong for me. [...] It's easier to just be in a moderate amount of pain but be able to focus because I'm used to that." (P18)

"I am trying to reduce the level of tramadol that I take. I've spoken to a doctor and she said, 'Well, try using codeine and paracetamol.' It's not the same. It is difficult. I don't know if anybody else has gone through trying to get the tramadol levels down, but that's a big challenge for me." (P17)

"I was taking quite a lot of co-codamol, to the point where it was probably getting into a dangerous direction, the amount of time that I'd spent taking it. So, now I try, where possible, just not to bother unless it's really quite severe." (P9)

Despite these negative impacts, analgesia was also reported as being one of the most effective ways of managing pain. 'Strong' analgesia (codeine and tramadol) was often used; those who do not want to rely on this still take paracetamol regularly as "it takes the edge off", but it is "not fully effective" (P19).

A positive mind set helped with accepting the pain. Participants reported that they feel "better off and stronger" because of haemophilia, and that while others "complain about trivial things such as catching a cold, haemophiliacs are stronger and they don't want pity" (P3).

\section{The impact of pain}

All participants were very familiar with pain, with their first experiences of pain usually described as starting 
when they were "very young" (P13) or "as a small child" (P17). Pain was a common element of daily life, with some experiencing pain at the time of the focus group they participated in. Given the extent and frequency of these experiences, it is not surprising that they have a strong impact on the participants' lives.

The impact of pain was discussed most in relation to its impact on participants' mental health and wellbeing.

"The mental health side, it's the process once you know you've had a bleed; it's that, 'Oh, here we go again.' You know it's going to be ... everyone knows by now it's going to be four or five days in bed doing this, this, and this, and you've got to go through that process. And also, just the general sense of kind of anger, disappointment at doing something again always annoys everybody, and that kind of just puts you in a downer. I think it's pretty hard to not be in a downer when you're having a bleed, so that just impacts your mental health. You'll be pretty upset, disappointed and angry for a couple of days while you're going through that initial point, and that affects everybody around you." (P2)

The impact on daily habits and routines was also discussed and mainly concerned the need to "protect [...] joints by not doing stuff" (P17). Several participants reported not being able to walk far, and if they did there were consequences:

"Any walking that I do, I pay for it every night and the next morning [...] I think the amount of pain you could have or you may have weighs heavily on the kinds of decisions you take on a daily basis." (P7)

Pain also impacted on sports and hobbies, with participants describing avoidance or reduction of participation in sports activities. Although low intensity activities such as yoga, cycling and walking can still be done, they take "a lot of willpower" (P1). Activities "which involve a lot of contact must be stopped" (P13). Participants' social life, work and education were similarly impacted. This included having to take time off work and "missing quite a bit of school time" (P5):

"I'm at college and it's hard to explain to people why you're taking so much time off [...] And you're just there, like, yes, your learning is impacted a hell of a lot, but you need it to rest." (P1)
"I find I always try and compare myself to other people at work and sport and things, and I think I don't want to be the one who's always having sick days, I don't want to be the one who's taking that time off." (P5)

\section{DISCUSSION}

Pain is a well-recognised side effect of bleeding in $\mathrm{PWH}$. Acute pain following bleeding and chronic pain is associated with haemophilic arthropathy and joint disease due to recurrent bleeds. There are many publications that address pain in haemophilia, with prevalence quoted at between 17-84\% for acute pain and $46 \%$ for chronic pain ${ }^{[13]}$. Whilst many studies have assessed pain using validated assessment tools ${ }^{[7,14,15]}$, few have interviewed PWH to ask about their pain and pain experience. In this study, we aimed to identify the impact of pain on PWH in the UK and to describe their perceptions about current pain management by haemophilia HCPs. We identified three key overarching themes: factors influencing the experience of pain, ways to manage pain, and the impact of pain. Participants reported longstanding pain memories, remembering pain being present from childhood following bleeds. This has been shown in other studies ${ }^{[10,16]}$ and is known to affect long-term physical and mental health by impacting on daily routine and hobbies. PWH reporting higher pain levels have also been shown to report worse health using patient reported outcome measures compared to peers with haemophilia and no pain ${ }^{[17]}$. In our study even young PWH treated with intensive prophylaxis and apparently 'good' joint health reported pain. This is contrary to previous findings reporting that treatment adherence improved chronic pain ${ }^{[18]}$.

Living with the memory of pain since childhood led many participants to state that they accepted their pain and just got on with living a life in pain. Participants were able to differentiate between the pain of acute bleeds, for which they would use factor infusions and analgesia, and that of arthritic damage, where they reported a reluctance to take analgesia but often did because the pain was unrelenting. This differs from the findings of Witkop et al., who showed that factor replacement was used $38 \%$ of the time for pain management ${ }^{[19]}$. Study participants who reported using opioid analgesia expressed concern that HCPs prescribed these drugs in a seemingly 'free' manner, with little if any discussion of other means of symptom relief, advanced pain assessment and/or management. They reported a dislike of pain assessment using pain 
scales, particularly those using faces to represent pain severity, saying that these felt meaningless as individual scores would mean different things to each individual with haemophilia. Di Minno et al. describe 'limited validated guidelines' for the management of pain in haemophilia and ask whether pain specialists should be part of the haemophilia team ${ }^{[20]}$. A recent study involving HCPs has described how haemophilia and pain management are discordant, with limited pain management options for PWH ${ }^{[21]}$. Whilst guidelines may help to improve pain assessment, they may not be the appropriate manner in which to address the physiological and psychosocial aspects of pain experienced by $\mathrm{PWH}^{[22]}$.

Although there were some negative comments about HCPs in our study with regard to pain management in haemophilia care, conversely, participants shared positive comments about physiotherapists. There is currently limited evidence for the role of physiotherapy in addressing pain in PWH ${ }^{[15]}$. However, in our study, physiotherapists were stated as having been helpful in supporting $\mathrm{PWH}$ to be active (even with pain) and encouraging individualised rehabilitation and mobility.

Talking about pain was seen as important - sharing experiences with others with haemophilia was described as supportive for those affected but also educational for PWH in the future. Despite a call to action to prioritise pain management in haemophilia care, including development of haemophilia specific assessment tools ${ }^{[23]}$, there remains a paucity of published in-depth data exploring PWH's views of living with current and past experiences of pain ${ }^{[24]}$. Addressing this is a role that patient support organisations should embrace along with patient education and support ${ }^{[25]}$.

\section{CONCLUSION}

Acute pain in haemophilia related to bleeding is well recognised. Recurrent joint bleeding leads to chronic pain which becomes 'normal' for PWH who "become used to this kind of pain" (P7) and adopt it into part of their everyday life experience. HCPS are ideally placed to impact on this experience but according to study participants they seem to lack insight into the extent of pain and how to manage it beyond prescribing stronger analgesia, which $\mathrm{PWH}$ find unacceptable due to side effects. The social and psychological implications of chronic pain should be better addressed by the haemophilia multidisciplinary team. This includes increased awareness of pain in
PWH and mechanisms for treatment beyond analgesia, such as physiotherapy and psychological support. This is an area ripe for future research and should include children and those treated with primary prophylaxis as well as those with obvious joint disease.

The participants in this study reported few recent bleeds; their chronic pain is related to joint damage which occurred in their pasts, pre- prophylaxis as standard of care. It is important to recognise this as we move into an era of even better treatment of haemophilia - the majority in this study were treated with 'new therapies' using extended half-life (EHL) clotting factors and bi-specific antibody treatments. We need to be cognisant that new therapies will not resolve old pain.

\section{LIMITATION}

This is a small qualitative study of PWH in the UK. We have not tried to compare our results with other conditions/general populations as study groups would not be comparable.

\section{ACKNOWLEDGEMENTS}

We would like to thank the focus group participants for sharing their time and stories for this project. Informed consent has been obtained from the participants in the study reported in this paper.

\section{Funding}

The Perceptions of Pain in Haemophilia study was funded jointly by Sobi UK and Roche Products Limited and Chugai Pharma UK Ltd.

\section{DATA SHARING}

The data that support the findings of this study are available from the corresponding author upon reasonable request.

\section{ORCID}

Kate Khair (iD https://orcid.org/0000-0003-2001-5958

Mike Holland (iD https://orcid.org/0000-0002-9173-4100

\section{REFERENCES}

1. McCaffery M Beebe A. Pain: Clinical Manual for Nursing Practice. 1989. St Louis: CV Mosby.

2. Srinivasa NR, Carr DB, Cohen $M$, et al. The revised International Association for the Study of Pain definition of pain: concepts, challenges and compromises. Pain 2020; 161(9): 1976-1982. doi: 10.1097/j.pain. 0000000000001939.

3. Khair K (Host). (2021, February 22). We don't ask. They don't tell - Pain and haemophilia (Part 2). In Haemcast. Haemnet. https://anchor.fm/haemnet/episodes/We-dont-ask--They- 
dont-tell---Pain-and-haemophilia-Part-2-eqak60 (accessed 14 September 2021)

4. Tagliaferi A, Franchinin M, Rivolta GF, Farace S, Quintavalle G, Copploa A. Pain assessment and management in haemophilia: A survey among Italian patients and specialist physicians. Haemophilia 2018; 24(5): 766-773. doi: 10.1111/hae.13600.

5. Humphries TJ, Kessler CM. The challenge of pain evaluation in haemophilia: can pain evaluation and quantification be improved by using pain instruments from other clinical situations? Haemophilia 2013; 19(2): 181-7. doi: 10.1111/ hae.12023.

6. Holstein K, Klamroth R, Richards M, Carvalho M, Perez-Garrido $\mathrm{R}$, Gringeri A. Pain management in patients with haemophilia: a European survey. Haemophilia 2012; 18: 743-752. doi: 10.1111/j.1365-2516.2012.02808.x.

7. Witkop M, Neff A, Buckner TW, et al. Self-reported prevalence, description and management of pain in adults with haemophilia: methods, demographics and results from the Pain, Functional Impairment, and Quality of life (P-FiQ) study. Haemophilia 2017; 23(4): 556-565. doi: 10.1111/hae.13214.

8. Pinto PR, Paredes AC, Almeida A. Pain prevalence, characteristics, and impact among people with hemophilia: Findings from the first Portuguese survey and implications for pain management. Pain Med 2020; 21(3): 458-471. doi 10.1093/pm/pny309.

9. van Genderen FR, Fischer K, Heijnen L, et al. Pain and functional limitations in patients with severe haemophilia. Haemophilia. 2006; 12(2): 147-53. doi: 10.1111/j.13652516.2006.01203.x.

10. Rambod M, Forsyth K, Sharif F, Khair K. Assessment and management of pain in children and adolescents with bleeding disorders: A cross-sectional study from three haemophilia centres. Haemophilia 2016; 22(1): 65-71. doi: 10.111/hae.12765.

11. Khair K, Bladen M, Holland M. Physical function and quality of life in adolescents with haemophilia (SO-FIT study). J Haem Pract 2014; 1(2): 11-14. doi: 10.17225/jhp00018.

12. Khair K, Holland M, Bladen M, Griffioen A, McLaughlin P, von Mackensen S. Study Of physical Function In adolescenTs with Haemophilia: the SO-FIT Study. Haemophilia 2017; 23(6): 918925. doi: 10.1111/hae.13323.

13. Paredes AC, Teixeira P, Almeida A, Pinto PR. Prevalence and interference of chronic pain among people with hemophilia: A systematic review and meta-analysis. J Pain 2021 May 1:S1526-5900(21)00212-1. doi: 10.1016/j.jpain.2021.03.157. Epub ahead of print.

14. Ucero-Lozano R, López-Pina JA, Ortiz-Pérez A, CuestaBarriuso R. The relationship between chronic pain and psychosocial aspects in patients with haemophilic arthropathy. A cross-sectional study. Haemophilia 2021 Dec 8. doi: 10.1111/ hae.14469. Epub ahead of print.

15. McLaughlin P, Hurley M, Chowdary P, Khair K, Stephensen $D$. Physiotherapy interventions for pain management in haemophilia: A systematic review. Haemophilia 2020; 26(4): 667-684. doi: 10.1111/hae.14030
16. McLaughlin P, Hurley M, Chowdary P, Stephensen D, Khair $K$. How does a lifetime of painful experiences influence sensations and beliefs about pain in adults with severe haemophilia? A qualitative study. Disabil Rehabil 2021 Dec 24: 1-8. doi: 10.1080/09638288.2021.2018053. Epub ahead of print.

17. Barry V, Buckner TW, Lynch ME, et al. An evaluation of PROMIS health domains in adults with haemophilia: A cross-sectional study. Haemophilia 2021; 27(3): 375-382. doi: 10.1111/ hae.14321.

18. McLaughlin JM, Witkop ML, Lambing A, Anderson TL, Munn J, Tortella $\mathrm{B}$. Better adherence to prescribed treatment regimen is related to less chronic pain among adolescents and young adults with moderate or severe haemophilia. Haemophilia 2014; 20(4): 506-12. doi: 10.1111/hae.12360.

19. Witkop M, Lambing A, Kachalsky E, Divine G, Rushlow $D$, Dinnen J. Assessment of acute and persistent pain management in patients with haemophilia. Haemophilia 2011; 17(4): 612-9. doi: 10.1111/j.1365-2516.2010.02479.x.

20. Di Minno MND, Santoro C, Corcione A, et al.; HAEMODOL Study Group (Appendix 1). Pain assessment and management in Italian haemophilia centres. Blood Transfus 2020; 19(4): 335-42. doi: 10.2450/2020.0085-20.

21. McLaughlin P, Hurley M, Chowdary P, Stephensen D, Khair K. The experiences and beliefs of people with severe haemophilia and healthcare professionals on pain management, and their views of using exercise as an aspect of intervention: a qualitative study. Disabil Rehabil $2021 \mathrm{Dec}$ 24: 1-9. doi: 10.1080/09638288.2021.2018054. Epub ahead of print.

22. Roussel NA. Gaining insight into the complexity of pain in patients with haemophilia: State-of-the-art review on pain processing. Haemophilia 2018; 24 Suppl 6: 3-8. doi: 10.1111/ hae.13509

23. Humphries TJ, Kessler CM. Managing chronic pain in adults with haemophilia: current status and call to action. Haemophilia 2015; 21(1): 41-51. doi: 10.1111/hae.12526.

24. Wells AJ, Whitaker S, Gray D, Mangles S, Hislop-Lennie K, Stephensen D. Pain memories: A new concept to consider in the management of chronic pain in people with haemophilia. Haemophilia 2021 Dec 24. doi: 10.1111/hae.14480. Epub ahead of print.

25. Srivastava A, Santagostino E, Dougall A, et al.; WFH Guidelines for the Management of Hemophilia panelists and co-authors. WFH Guidelines for the Management of Hemophilia, 3rd edition. Haemophilia 2020; 26 Suppl 6: 1-158. doi: 10.1111/ hae.14046. Erratum in: Haemophilia 2021; 27(4): 699.

HOW TO CITE THIS ARTICLE:

Khair K, Kriukow J, Holland M. "It's a way of life": Results

from the Perceptions of Pain in Haemophilia study. J Haem Pract 2021; 8(1): 145-154. https://doi.org/10.2478/ jhp-2021-0020 


\begin{tabular}{|c|c|}
\hline Introduction & $\begin{array}{l}\text { - Introduce self and study } \\
\text { - Emphasise non-judgemental position, discussion not a Q\&A } \\
\text { - Assure confidentiality } \\
\text { - Check permission to record the conversations; direct quotes will be } \\
\text { used but will be fully anonymised }\end{array}$ \\
\hline Background information & $\begin{array}{l}\text { - Invite the participants to introduce themselves (include age and where } \\
\text { they are currently living, type and severity of haemophilia, current } \\
\text { treatment) }\end{array}$ \\
\hline The lived experience of having pain & $\begin{array}{l}\text { - Can you tell us about your first memories of (joint) bleeding? } \\
\text { - How this was managed? } \\
\text { - When did they first realise they had pain? } \\
\text { - How many years ago is that? } \\
\text { - How/does it relate with their haemophilia? } \\
\text { - What impact on work, study, family life? } \\
\text { (PROBE) } \\
\text { - Does it affect how active they are? } \\
\text { - How much? } \\
\text { - Why? } \\
\text { - Would you like to do more? }\end{array}$ \\
\hline Who do you talk to about your pain? & $\begin{array}{l}\text { - Do your haemophilia treaters ask about pain? } \\
\text { - Do you use pain assessment tools? } \\
\text { - Are these useful (why/why not?)? } \\
\text { - If not, why not? } \\
\text { - If yes, how do they respond? What have you been told? } \\
\text { (PROBE) } \\
\text { - Who in the team is interested in pain? } \\
\text { - Anyone else - GP, etc? } \\
\text { - What do you do/use to manage pain? }\end{array}$ \\
\hline How do you manage your pain? & $\begin{array}{l}\text { - Do they use factor concentrate/treatment for analgesic effect? } \\
\text { - Do they use OTC meds/street drugs? } \\
\text { - What have you done previously? } \\
\text { - Why did they choose these? } \\
\text { (PROBE) } \\
\text { - Did anything work well? } \\
\text { - Why do they think it worked? } \\
\text { - What did not work - why not? }\end{array}$ \\
\hline What is causing the pain & $\begin{array}{l}\text { - Why do you think you have pain? } \\
\text { (PROBE) } \\
\text { - Have you noticed any particular things that happen to make you have } \\
\text { more pain? } \\
\text { - What is the relationship between these events and your pain? } \\
\text { - Do you think your pain can be made easier/managed better? And how? }\end{array}$ \\
\hline Close & $\begin{array}{l}\text { - Have you any questions or thoughts to add about the things we have } \\
\text { discussed today? } \\
\text { - Thanks for participating and next steps }\end{array}$ \\
\hline
\end{tabular}

